\title{
Saúde Comunitária e Metodologias Participativas na formaçáo e atuaçáo com a temática do uso de drogas: Relato de experiência
}

\author{
Community Health and Participatory Methods in training and \\ acting with the theme of drug use: Experience report
}

Pedro Henrique Antunes da Costa ${ }^{\mathrm{I}}$

\section{Resumo}

O presente trabalho objetiva relatar e discutir uma experiência de formação sobre a temática do uso de drogas para profissionais da saúde, assistência social e educação, articulada com as necessidades dos territórios e comunidades, de modo a possibilitar práticas contextualizadas sobre o tema. Para isso, se ancorou na Saúde Comunitária (SC), lançando mão de Metodologias Participativas (MP) na produção de conhecimento, avaliação e potencialização do processo. Mesmo num contexto societário antagônico às premissas de ambas, demonstrou-se as potencialidades da SC, materializada por meio da MP, para a formação e atuação conjuntas, contextualizadas e abrangentes sobre a temática do uso de drogas e suas múltiplas interfaces, circunscritas à realidade sociocomunitária e tendo na transformação de suas necessidades os elementos norteadores.

Palavras chave: psicologia comunitária; formação profissional; educação permanente; participação; drogas

\begin{abstract}
The present article aims to report and discuss a training experience on the theme of drug use for health, social assistance and education professionals, articulated with the needs of the territories and communities, in order to allow contextualized community practices on the theme. For that, it was anchored in Community Health (SC), using Participatory Methods (MP) in the production of knowledge, evaluation and potentialization of the process. Even in a societal context antagonistic to the premises of both, it was demonstrated the potential of SC, materialized through MP, for joint, contextualized and comprehensive training and action on drug use and its multiple interfaces, circumscribed to socio-community reality and having in the transformation of its needs the guiding elements.
\end{abstract}

Keywords: community psychology; professional education; continuing education; participation; drugs

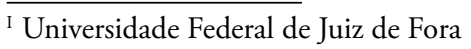

É constatada e recorrente na literatura acadêmica a insuficiência de formação profissional concernente à temática do uso de drogas, reverberando, dentre outros fatores, em práticas profissionais igualmente incipientes e limítrofes (Moretti-Pires, Lima \& Katsurayama, 2010; Vargas \& Duarte, 2011; Costa et al., 2015; Costa \& Paiva, 2016a). Tal cenário não se restringe à saúde e também é observado com relação a outras temáticas que dizem respeito à realidade social complexa e multifacetada em que vivemos, extrapolando, portanto, concepçóes fragmentadas, que reduzem o ser humano a determinadas dimensóes (biológicas e/ou psicológicas), fomentadas por meros processos de transferência e aquisição de conhecimentos técnicos descompromissados socialmente (Ronzani, 2007; Kanno, Bellodi \& Tess, 2012; Almeida Filho, 2013). Assim, nos deparamos com uma grande contradiçáo, onde profissóes e campos do saber que se debruçam e tomam como objeto de estudo e intervenção o ser humano e seu contexto de vida, não possuem formação suficiente para abarcar justamente estes sujeitos, suas realidades e necessidades. Logo, nos questionamos que sujeitos e contextos são estes que - supostamente - orientam nossas formulaçóes teórico-conceituais e práticas?
Será que correspondem, de fato, à realidade ou se tratam de meras abstraçóes descontextualizadas?

Diante deste panorama, por mais que impere a necessidade de reflexáo e reformulação da formação profissional para atuar com os sujeitos e suas condições de existência, ela não deve ser pensada isoladamente, de forma autocentrada, muito menos descolada de nossa atual conjuntura social e histórica. É premente entender que a própria formação profissional hegemônica insuficiente nestes campos (saúde, assistência social, educação etc.) aparece como reflexo dessa configuração societária contribuindo, reflexivamente, para a sua manutenção, isto é, corroborando com a ordem social. Logo, somente a disponibilização de cursos, capacitaçóes e alteraçóes curriculares também são insuficientes se não estiverem assentadas na própria problematização da realidade sob a qual se inserem e visam subsidiar transformações, potencializados por meio de perspectivas participativas, horizontais e abertas às demandas das pessoas, dos cotidianos de vida e trabalho (Costa et al., 2015; Paiva \& Costa, 2016b).

No que se refere ao uso de drogas, tais pressuposiçôes denotam a imprescindibilidade de se conceber este fenômeno a partir das condiçôes sociais e históricas 
nas quais se constitui e contribui para conformar, com a necessidade de compreendê-lo inserido dentro de uma totalidade social, estabelecendo relaçóes dialéticas com ela e com outros fenômenos que nesta realidade incidem. Assim, é possível romper com racionalidades e propostas de atuação sobre o tema orientadas pelo modelo biomédico hegemônico, que se nutrem de naturalizaçóes e individualizaçóes de sua complexidade e multidimensionalidade, juntamente com concepçóes moralistas e estigmatizantes (Moraes, 2008; Schneider, 2010; Paiva \& Costa, 2016b)

Considerando o panorama apresentado, a Saúde Comunitária (SC) desponta como uma perspectiva recente no âmbito da saúde pública de reversão da compreensão e atuação sobre o processo saúde-doença e que, portanto, pode auxiliar também nas reflexóes e reformulaçôes não só da formação na área, mas, principalmente, nas formas como abordamos a temática do uso de drogas, desde as formulaçóes teórico-conceituais existentes, chegando nas políticas públicas, serviços e práticas profissionais cotidianas. Ao se direcionar para a tomada de consciência das comunidades acerca de suas próprias condiçóes de saúde, tomando-os como atores centrais de suas vidas (Saforcada, 2008; 2012), a SC possibilita, por consequência, um maior esclarecimento e conscientização sobre o tema do uso de drogas, dentre outros que conformam a realidade sociocomunitária.

Conforme postula Saforcada (2008), a SC surge na América Latina (AL) de baixo para cima, a partir das necessidades e reivindicaçôes da população em geral, sobretudo, daquelas marginalizadas, despossuídas, afetadas diretamente pela desigualdade estrutural que assola nosso continente. Por conta disso, trata-se de um movimento contra hegemônico, cabendo à academia, ao Estado e suas instâncias compreendê-lo e incorporá-lo numa perspectiva participativa e horizontal, que agregue a comunidade e os saberes populares como elementos ativos e centrais, repensando, inclusive, seus papeis na sociedade e em nossa conjuntura, o que implica, no caso da academia, em reflexôes e reformulações não só sobre as formas de produção de conhecimento estritas, mas, principalmente, acerca da sua indissociabilidade com a modificaçáo a essa realidade na qual se assenta.

Referente aos processos de produção de conhecimento e intervenção na realidade, tais sinalizaçôes proveniente da SC denotam a necessidade de se refletir náo somente acerca das dimensôes ontológica, epistemológica e metodológica existentes, mas também considerar sobre outras duas de igual relevância, mas frequentemente desconsideradas ou minimizadas: a dimensão ética e a política (Montero, 2004). Isso significa pensar nos horizontes e nas possíveis implicações/reverberaçóes existentes deste processo de contato ou inserção em uma dada realidade, ou com determinado fenômeno, com o intuito de compreendê-los e/ou modifica-los.

Nessa direção, as metodologias participativas (MP) aparecem em conformidade com a SC e se consolidam como possibilidades de materializaçáo de suas premissas, sendo caracterizadas sob variadas alcunhas, tais como: pesquisa-ação, pesquisa-intervenção, pesquisa-participante, pesquisa-ação-participante etc. Possuem suas origens frequentemente associadas à Kurt Lewin, na década de 30 nos Estados Unidos, mas se desenvolvem e disseminam também pela Europa e, principalmente, na AL no século XX, onde adquirem um caráter crítico visando a transformação social e libertação popular. Dentre vários nomes importantes para o seu desenvolvimento na AL podemos citar Orlando Fals-Borda, sua sociologia crítica e as metodologias de pesquisa-açáo participativas formuladas por ele, e também Paulo Freire e sua Pedagogia/Educação Popular (Rocha \& Aguiar, 2003; Sarriera, 2010)

Em linhas gerais, as MP possibilitam, assim como propóe a SC, o estabelecimento de uma nova relaçáo entre a ciência e a realidade social, assim como entre a academia e a sociedade em geral, concebendo-os relacional e dialeticamente imbricados, ao invés de instâncias fragmentadas e dicotômicas. Além disso, objetivam modificar a visão clássica de ciência, tomando-a como uma prática social, juntamente com reversão da tradicional separação importada das ciências naturais da relação entre sujeito-objeto, onde inicialmente pesquisamos determinados fenômenos para depois agir sobre eles (Sarriera, 2010; Uzzell \& Barnett, 2010).

Portanto, a partir da confluência entre a SC e as MP, é possível potencializar não só a formação no que diz respeito à temática do uso de drogas, mas também a reflexão conjunta sobre como este fenômeno se expressa nos contextos sociocomunitários e, portanto, pode ser abarcado pelos sujeitos por ele perpassado. A partir do exposto anteriormente, o presente trabalho objetiva relatar e discutir uma experiência de formação sobre a temática do uso de drogas e suas interfaces para profissionais da saúde, assistência social e educação, articulada com as necessidades dos territórios e comunidades, de modo a possibilitar práticas comunitárias contextualizadas sobre o tema. Para isso, se ancorou na SC, lançando mão de MP na produção de conhecimento, avaliação e potencialização do processo. 
Pensando o Processo de Formação e Atuação: Aportes da Saúde Comunitária e o Papel das Metodologias Participativas

O presente trabalho é oriundo de um projeto de extensão que, conforme mencionado, voltou-se para a formaçáo e atuaçáo com a temática das drogas em contexto sociocomunitário. A partir da fundamentação na Saúde Comunitária (Góis, 2007; Saforcada, 2008; 2012; Saforcada \& Alves, 2015) e suas interfaces com outros complexos do saber e âmbitos de prática, como a Psicologia Comunitária (Martin-Baró, 1990/1996; Freitas, 1998; Montero, 2004), a Educação Popular freireana (Freire, 2005) e a Educação Permanente (Ceccim, 2005), foi delimitado o horizonte de abordagem à temática do uso de drogas nos contextos comunitários supracitados. Dessa forma, os seguintes pontos conformaram-se como pressuposiçóes basilares para o planejamento e realização do trabalho: (a) a superaçáo do paradigma de saúde pública tradicionalmente pautado por um modelo biomédico individualizante hegemônico com enfoque nas ações de controle e curativistas, desconsiderando práticas de promoção de saúde e prevençáo e também; (b) o aprofundamento dos avanços propiciados pela Saúde Coletiva em direção à centralidade da comunidade na conduçáo de suas próprias vidas, ao invés das equipes profissionais da saúde; (c) a concepção e a abordagem do ser humano, do processo saúde-doença, e, por conseguinte, da temática do uso de drogas, não se dão per si, como se se desenvolvessem e constituíssem num vácuo sócio histórico, mas atreladas a determinadas lógicas e configuraçôes societárias e suas contradiçôes (Costa \& Paiva, 2016b).

Adicionalmente, de acordo com Freitas (1998), as preocupaçóes motivadoras do trabalho não estavam atreladas somente à produção de conhecimento, como nos moldes tradicionais de se fazer pesquisa, mas também à modificaçáo dos contextos supracitados, com vistas à qualificação da formação dos profissionais, propiciando uma abordagem realista, desnaturalizante, não moralizante e abrangente sobre a temática do uso de drogas e suas múltiplas interfaces. Nesse sentido, o conceito de práxis como ação-reflexáo dentro do movimento da história, orientada para a transformação, torna-se fundamental. Isso significa questionar que tipo de intervenção pretende-se fomentar e realizar, implicando em uma resposta que passe, impreterivelmente, pela coparticipação da comunidade, com definição a posteriori dos objetivos, buscando produçóes de conhecimento e açóes conjuntas e mediando os possíveis ônus e ganhos (Freitas, 1998).
Embebidas por tal racionalidade, formação e atuação não encontram-se desconectadas, mas se interrelacionam dialética e processualmente. E, por sua vez, ambas também devem ser compreendidas inseridas em uma totalidade social, isto é, em nossa realidade sociocultural e, mais especificamente, nos contextos comunitários que são dinâmicos. Portanto, ao invés fomentarmos/reproduzirmos a lógica tradicional de formulação e implementação das políticas públicas e sociais, que veem os policymakers, as gestão e os profissionais como seus pensadores e executores, sendo a população uma mera receptora de benesses, a lógica orientadora passa pela construçáo dialógica, a partir das necessidades dos territórios e comunidades, considerando, inclusive, que devolver o poder de decisão às populaçóes no que diz respeito à suas vidas constitui-se em uma forma de contribuir para um avanço de conscientização e na emancipação destes sujeitos e cenários (Saforcada, 2008; Saforcada \& Alves, 2015).

Logo, mesmo um processo de formação-atuação que, em tese, esteja voltado para os profissionais das políticas públicas, sabe-se que suas açôes têm uma temporalidade, um contexto e são direcionadas a sujeitos concretos, com necessidades, sendo estes os elementos norteadores Dessa forma, a formaçáo e a atuação não são fins em si mesmas, fazendo com que a práxis profissional seja abordada como instrumento de potencialização do contexto sociocomunitário, o que nos leva a indagar, em consonância com Martin-Baró (1990/1996), em benefício de quem essa práxis se erige e quais são as consequências históricas das açôes as quais se deseja substanciar e potencializar.

Considerando os fatores supracitados, o modelo pensado para a contextualização das práticas formativas e de ação nas comunidades foi estruturado nos seguintes passos: 1) Identificação e mapeamento dos recursos comunitários existentes, p. ex. atores sociais, redes sociocomunitárias, dispositivos e instituiçóes parceiras presentes nos territórios etc.; 2) Realização de diagnósticos participativos acerca das características locais com os recursos comunitários identificados; 3) Elaboração conjunta das ações; 4) Execução também coletiva das açôes; e 5) Avaliação durante todo o processo, sendo feita também coletivamente.

A MP foi utilizada durante todo este processo, como forma de materializar algumas das premissas da SC, possibilitando uma co-construção dialógica/horizontal, servindo também como recursos avaliativos, de modo a produzir conhecimentos que balizassem as açóes realizadas, municiando-as de maior contextualidade (Streck, 2016). Para tanto, os motivos para a utilização 
dos métodos, assim como as formas que foram empregados e os resultados gerados, foram pensados, acordados e avaliados constantemente por todos os participantes, a partir das necessidades identificadas.

Neste contexto, a observação participante foi a principal estratégia metodológica empregada (Valladares, 2007), por meio de visitas semanais aos serviços e comunidades, acompanhamento e suporte à atuaçáo dos profissionais nos territórios, conversas informais com atores locais, e tendo no diário de campo o instrumento fundamental de registro e síntese dos dados produzidos. Conjuntamente à observação participante, outras possibilidades metodológicas foram pactuadas com os profissionais, usuários dos serviços $\mathrm{e}$ a comunidade em geral, como a utilização do Ecomapa como ferramenta de compreensão sobre a rede assistencial e mapeamento e identificação dos recursos comunitários existentes nas realidades abrangidas.

\section{RESULTADOS, REFLEXÓES E INQUIETAÇÓES}

A presente experiência formativa e de atuação foi realizada, durante os anos de 2015 e 2016, em duas regióes de um município de médio porte da Zona Mata mineira, conduzida por um grupo de pesquisadoresextensionistas, vinculados a um centro de pesquisas e intervenção de uma Instituição Pública de Ensino Superior de Minas Gerais. A escolha destas regióes se deu por conta dos seguintes fatores: (a) impossibilidade de abarcar o município como um todo, ainda mais quando levamos em consideração a necessidade de compreensão e atuação contextualizadas; (b) os acentuados indicadores de vulnerabilidade social em ambas as regiōes; e (c) as redes de proteção básica do Sistema Único de Assistência Social (SUAS), sendo estas as duas únicas regiōes do município com mais de um Centro de Referência da Assistência Social (CRAS) - dois em cada -, o que potencializava o processo de inserção e familiarização, assim como a ação intersetorial. Posteriormente, almejando maior profundidade e contextualidade nas açóes, as regióes foram divididas cada uma em dois territórios, totalizando, portanto, quatro territórios de ação.

Além de possibilitar momentos formativos de trocas teórico-práticas com 211 profissionais de cerca de 30 serviços da educação (escolas municipais e estaduais), do Sistema Único de Saúde (SUS) e SUAS, o presente processo formativo, por meio das reflexóes propiciadas tanto pela SC quanto pela utilização da MP, também atuou nos seguintes pontos: (a) criaçáo de espaços permanentes de trocas e apoio, como reunióes com a rede assistencial e a comunidade; (b) acompanhamento do processo de proposição e implementação das açóes relacionadas ao uso de drogas e outras temáticas de interface oriundas da própria comunidade; (c) auxílio na implementação das açôes de promoção de saúde e social, prevenção e assistência sobre os problemas relacionados ao uso de drogas das políticas locais, através da integração entre comunidades e diversos setores e profissionais.

A partir destas dimensóes, foram realizados projetos de sensibilização e intervenção sobre o tema com as comunidades, açôes educativas, oficinas, grupos de prevenção no contexto dos serviços, capacitaçóes com os profissionais sobre temáticas vivenciadas em sua realidade cotidiana, rodas de conversa com profissionais e população em geral, ações com jovens e adolescentes estudantes das escolas abarcadas, dentre outros. Em um território em específico, a atuação com os adolescentes conseguiu, por meio do fomento de seus protagonismos pela MP, avançar para uma atuação conjunta e reflexiva acerca da própria realidade vivenciada cotidianamente por eles, indo para além da discussão sobre drogas, mas englobando assuntos, como: ser adolescente nas condiçôes em que vivem, raça/etnia e preconceito, o machismo e a posição da mulher em suas comunidades, desigualdade social e pobreza, a relação com a polícia, dentre outros. A partir das iniciativas de estudantes de uma escola, inclusive, o grêmio estudantil foi reativado. Cabe ressaltar somente que estas açôes são construçóes/realizaçóes dos sujeitos que destes processos fizeram parte, como os profissionais e atores comunitários, cabendo aos pesquisadores-extensionistas o papel de potencialização e auxílio para a sua concretização, conforme postula a SC (Góis, 2007; Saforcada, 2008; 2012; Saforcada \& Alves, 2015)

De modo geral, a utilização da MP abalizada pelos preceitos da SC, possibilitou uma formação-atuação conjuntas, atreladas à realidade sociocomunitária, com inserção nas comunidades, levantamento em conjunto das principais necessidades, assim como a articulação de diversos profissionais e atores que compóem a rede de atenção ao usuário de drogas e contextos comunitários referentes a duas regióes no município. Conduzido participativamente, tal processo possibilitou um aprofundamento e maior contextualização no processo de familiarização e conhecimento sobre as realidades, em suma, uma formação-atuação porosa e direcionada aos territórios (Ceccim, 2005), implicando em reflexôes e construções conjuntas entre profissionais, comunidade e os pesquisadores-extensionistas das açóes mais próximas às necessidades locais existentes.

Contudo, por mais que a participação comunitária se colocasse como um horizonte, sendo almejada 
durante todo o percurso por meio da MP, a construção e atuação conjunta com os usuários e comunidade em geral, sendo concebidos como atores ativos e definidores de suas próprias necessidades, apresentou-se como uma das limitaçôes do presente trabalho. Apesar dos avanços propiciados pela fundamentaçáo na $\mathrm{SC}$, atrelada às $\mathrm{MP}$ no planejamento, ação e avaliação, observou-se ainda um privilégio e centralidade nos profissionais, tomando quando possível - as instituiçôes como forma de acesso à comunidade. Tal limitação denota a influência dos pressupostos da Saúde Coletiva que, conforme Saforcada (2008), apesar de se caracterizar como um avanço considerável frente à perspectiva de saúde pública tradicional ainda toma as equipes profissionais (e aqui as expandimos para além da saúde) como os principais componentes de açáo, acessando a realidade e compreendendo-a demasiadamente sob seu ponto de vista.

Dessa forma, reside o desafio e, ao mesmo tempo, a necessidade de se pensar na participação não como um fim em si mesma, mas como meio; de se ampliar e fomentar uma concepção de participação comunitária náo limitada a apenas tomar parte dos processos de construção, decisão e ação, mas, sim, como uma forma de fomentar e potencializar - e aí a importância de se refletir constantemente sobre a $\mathrm{MP}$ - a apropriação e conscientizaçáo da comunidade acerca de sua própria vida, o que, consequentemente, reverberará nas práticas que nela incidem, sejam de saúde, da assistência social, educação etc. Assim, pode-se trabalhar com a comunidade, e não somente para ela (Saforcada, 2008; Góis, 2007), contribuindo para reverter os tradicionais privilégios e centralidade da gestão, profissionais e academia na formulação e implementação das políticas públicas, em direção a uma construção coletiva com os sujeitos que dessas políticas fazem parte e que considera a comunidade como principal componente de ação (Saforcada, 2012).

Ademais, conforma-se também como um elemento limítrofe o fato do presente projeto já possuir uma temática de interesse pré-estabelecida, como o uso de drogas, por mais que ela seja compreendida de forma abrangente, sendo multifacetada e possuindo interfaces com uma série de outros fenômenos. Por mais maleável que fosse a abordagem sobre o tema e suas interfaces, com a construçấo dos objetivos a posteriori e participativamente e que por conta da utilização da MP uma série de reformulaçóes tenha sido feita durante o processo como um todo, entende-se que as necessidades e as temáticas a serem abordados por um processo balizado pela SC devem advir do próprio contexto sociocomunitário. Conforme coloca Martin-Baró (1986/2011) e seu realismo crítico em oposição ao idealismo metodológico, é a realidade que serve como balizador e parametriza desde as formulaçôes teórico-conceituais até a ação que nela incide. Portanto, por meio dos resultados processuais obtidos pela MP com os profissionais, comunidade e de nossa própria reflexividade, mesmo os referenciais teóricos e as concepçôes sobre as temáticas de interesse tomados a princípio foram sempre elucubrados e, em alguns casos, até mesmo modificados, de modo a evitar cair em uma perspectiva que adeque o real ao ideal.

Não obstante, grande parte dos obstáculos enfrentados referem-se ao seguinte questionamento: Por mais que a MP e a SC estejam imbricadas e se interrelacionam, como pensa-las e colocá-las em prática num contexto societário que se configura de forma antagônica às premissas de ambas? Tais adversidades residem desde as concepçóes predominantes sobre o papel da academia e as formas de produçáo de conhecimento em geral, enviesadas por uma lógica de mercado funcional à ordem social e que concebe ambas isoladas da totalidade societária e, portanto, descompromissadas com a sua transformação (Streck, 2016). Numa relação de mútua influência, encontram-se as contradiçôes e limitaçôes das políticas públicas e sociais, acentuadas pelo próprio processo histórico de formação sociocultural brasileira e nossa realidade abruptamente desigual e antagônica, assim como pelo projeto neoliberal que aqui se instaurou a partir dos anos 90 e suas sucessivas (e em grande parte exitosas) açóes de desregulamentação e enfraquecimento da tentativa de Estado de bem-estar social que se intentou implantar por meio das lutas e movimentos sociais que culminaram na reabertura democrática e Constituição de 88 (Freitas, 2005; Ansara \& Dantas, 2010; Yamamoto, 2009; Yamamoto \& Oliveira, 2011; Behring \& Bochetti, 2011). Por fim, ainda incide nesse cenário a hegemonia do paradigma da saúde pública ancorado num modelo biomédico, que fracciona o ser humano e em partes e privilegia o saber médico e açóes curativistas, em detrimento da promoçáo de saúde, prevenção e uma perspectiva de trabalho inter ou transdisciplinar (Saforcada, 2008; Costa \& Paiva, 2016b).

Contudo, apesar das dificuldades impostas por este panorama, a ampliaçáo tanto do olhar sobre a realidade quanto da sua abordagem propiciadas pela SC e a utilização da MP, amplifica o leque de possibilidades de ação existentes, não só com relação à temática das drogas, mas no que se refere às condiçôes de vida da população e comunidades em geral. Esse alargamento teórico-conceitual e metodológico, a despeito da implicaçáo de se deparar com entraves que não seriam 
considerados numa atuação cristalizada, hierarquizada e acrítica, ao mesmo tempo, propicia uma abordagem abrangente e contextualizada, tomando os sujeitos e a comunidade como atores ativos de seus próprios processos de existência. Em suma, significa conceber e abordar a realidade como ela se constitui, o que pressupóe considerar e lidar suas contradiçóes/vicissitudes, ao invés de naturalizá-las.

Concomitantemente, as interfaces entre a SC e a MP no presente trabalho denotam a grande limitação e ineficiência que as açôes ditas de "capacitação", com modelos e conteúdos pré-moldados e pautadas na transmissão vertical de conhecimentos, possuem de reverberarem nas práticas e modificarem a realidade (Costa et al., 2015). Afinal, mesmo com toda essa proposta contextualizada e participativa, os obstáculos foram numerosos, incutindo em uma série de percalços, com a necessidade de exercícios constantes de reflexão e reformulação, o que fez o percurso parecer mais um caminho de idas e vindas do que algo linear. Logo, não seria ainda mais limítrofe uma proposta de formação engessada, pautada no modelo clássico de ensino-aprendizagem escolar hierarquizado - como Paulo Freire (2005) nomeia, uma educação bancária -, que desconsiderasse a necessidade de adequação aos contextos sociocomunitários, assim como todo o conhecimento teórico-prático dos sujeitos que dessa realidade experienciam cotidianamente?

Além disso, o presente trabalho e suas fundamentaçóes demonstram que mesmo em ações que, a princípio, podem se caracterizar como de extensão, é possível produzir conhecimento, e mais, um conhecimento orientado e socialmente compromissado com a modificação da realidade, dentro dos limites existentes das especificidades locais e da própria ordem social. Isto reforça a concepçáo da práxis e a necessidade de uma perspectiva integrada e indissociável de reflexãoaçáo, com estas instâncias sendo insuficientes quando separadas uma da outra. Tal constatação serve não só para a extensão, mas também para as pesquisas que vão para além da produção de conhecimento estritamente, visando a aplicação deste conhecimento produzido na transformaçáo de determinados fenômenos ou contextos. Sendo assim, em conformidade com Streck (2016), a qualidade deste conhecimento produzido não está diretamente relacionada à forma como ele é construído e o impacto que tem nesta realidade? Portanto, não é desejável que aquele(as) perpassados por suas implicaçóes sejam os seus co-construtores e alicerces? Ademais, segundo o mesmo autor, dessa forma, é possível resistir e fomentar outras formas de se produzir conhecimento que não as pautadas pelo produtivismo acadêmico, que dicotomizam produtores e consumidores ou usuários de pesquisa (Streck, 2016).

Por fim, tal processo mostra-se coerente com uma visão abrangente sobre a temática do uso de drogas, concebendo-o não como uma "questão" ou problema a priori e em si, mas como um fenômeno imbricado em nossa ordem societária e, que, portanto, não pode ser abordado isoladamente dela e das outras "questôes" que dela se erigem e se multideterminam reflexivamente, perpassando as vidas das pessoas. Isto é, como um complexo circunscrito a outro complexo, que é a nossa totalidade social. Em consonância, ao se tratar de um fenômeno multifacetado, as tentativas de abarcá-lo devem ser orientadas por uma visão abrangente possibilitada pela lógica da integralidade, em detrimento de perspectivas setoriais fragmentadas e/ou açôes de serviços e profissionais isoladas, que o tomam frequentemente como um tema somente da segurança pública, da saúde, ou, até mesmo, de responsabilidade um único serviço.

Não obstante, esta perspectiva requer que lidemos com o possível, dentro das limitaçôes impostas por um contexto de uma irracional "Guerra contra as Drogas" que, na verdade, trata-se uma guerra contra pessoas, um genocídio a determinadas parcelas da população, sobretudo os/as jovens, negros/as e pobres. Significa lidar com o assunto onde ele se constituiu, ou seja, nas realidades concretas das comunidades e com os sujeitos que ali se encontram, mesmo que isso signifique se deparar com todas as suas contradiçóes, como, por exemplo, a disputa entre vieses de saúde versus perspectivas criminalizantes, visóes contextualizadas versus preconceitos, estigmas e moralismos, se debruçando concretamente sobre a barbárie que aflige uma grande parcela da população brasileira - direta ou indiretamente. Assim, como saída, vislumbramos conjuntamente o possível, através da sobreposição do real ao ideal. E neste processo, a comunidade exerce papel central para a construção e implementação de formas de se abarcar os dilemas que ainda persistem em dificultar a potencialização humana, sendo o uso de drogas somente um deles. Afinal, ninguém sabe melhor sobre si e seu processo de constituição do que as próprias pessoas, do que a própria comunidade na qual se visa intervir conjuntamente.

\section{CONSIDERAÇÓES FINAIS}

Em síntese, o presente trabalho demonstrou as potencialidades da SC como perspectiva balizadora 
não só na saúde, mas nas políticas públicas em geral. Materializada por meio da utilização da MP, possibilita uma formação e atuação conjuntas, contextualizadas e abrangentes sobre a temática do uso de drogas e suas múltiplas interfaces, circunscrita à realidade sociocomunitária. Nesse sentido, por mais que os processos formativos e de ação estejam voltados a princípio para os profissionais, a comunidade é tomada como elemento central destes processos e não somente como um ator passivo frente às suas próprias condiçôes de vida, tendo na transformação de suas necessidades os elementos norteadores.

Nesse sentido, o percurso aqui apresentado e discutido reflete um caminho ainda inicial e incipiente em direçáo à concretização dos pressupostos da SC, trazendo consigo todas as vicissitudes e obstáculos referentes a esse processo de ampliação do horizonte práxico numa realidade social antagônica a propostas como estas, perpassada por uma série de determinantes limítrofes e constritores da própria potência e ação humana. Justamente por conta desse seu caráter, dialeticamente, também traz consigo um conjunto de potencialidades advindas desse processo de reformulaçáo do olhar tradicional assistencialista fomentado na saúde e políticas públicas em geral, que toma a comunidade e a população em geral como meros objetos de manipulação e/ou receptores de açóes.

Dessa forma, amplia-se o leque de possibilidades para uma formaçáo e atuação profissional comprometida com a análise crítica do contexto na qual se insere, o conforma e é conformado, em conjunto com a premência de sua modificação em direção a cenários mais dialógicos e equânimes, dentro das limitaçôes da ordem social posta. Afinal, a práxis sociocomunitária não se configura como algo dissociado da realidade e, portanto, dos meios que a conformam e que dela resultam. Dessa forma, suas ferramentas encontram-se localizadas nessa própria realidade, seus sujeitos, grupos e comunidades.

\section{REFERÊNCIAS}

Ansara, S., \& Dantas, B. S. A. (2010). Intervençóes psicossociais na comunidade: desafios e práticas. Psicologia \& Sociedade, 22(1), 95-103.

Behring, E., \& Boschetti, I. (2011). Politica Social: fundamentos e história. 9a ed. São Paulo: Cortez Editora.

Ceccim, R. B. (2005). Educação Permanente em Saúde: desafio ambicioso e necessário. Interface (Botucatu), 9(16), 161-168.

Costa, P. H. A., Mota, D. C. B., Cruvinel, E., Paiva, F. S., Gomide, H. P., Souza, I. C. W., et al. (2015). Capacitação em álcool e outras drogas para profissionais da saúde e assistência social: relato de experiência. Interface (Botucatu), 19(53), 395-404.

Costa, P. H. A., Laport, T. J., \& Paiva, F. S. (2015). Perspectivas sobre o trabalho em rede: contribuiçôes do paradigma ecológico no processo de intervenção em álcool e outras drogas. In: Ronzani, T. M., Costa, P. H. A., Mota, D. C. B., \& Laport, T. J. (Orgs.). Redes de Atenção aos Usuários de Drogas - Políticas e Práticas (pp. 189-218). São Paulo: Cortez Editora.

Costa, P. H. A., \& Paiva, F. S. (2016a). A formação profissional para o trabalho na área de álcool e outras drogas: reflexôes a partir do Programa de Educação pelo Trabalho para a Saúde. Pesquisas e Práticas Psicossociais, 11(3), 539-551.

Costa, P. H. A., \& Paiva, F. S. (2016b). Revisão de literatura das concepçóes dos profissionais de saúde sobre o uso de drogas: modelo biomédico, naturalizaçôes e moralismos. Physis, 26(3), 1009-1031.

Freire, P. (2005). Pedagogia do oprimido. 50 ed. Rio de Janeiro: Paz e Terra.

Freitas, M. F. Q. (1998). Inserção na comunidade e análise de necessidades: reflexôes sobre a prática do psicólogo. Psicol. Reflex. Crit., 11(1), 0.

Freitas, M. F.Q. (2005). (In)coerências entre práticas psicossociais em comunidade e projetos de transformação social: aproximaçóes entre as Psicologias Sociais da Libertação e Comunitária. Revista Psico, 1(36), 47-54.

Góis, C. W. L. (2007). Saúde Comunitária: Pensar e fazer. São Paulo: Hucitec.

Martín-Baró, I. (1990/1996). O papel do Psicólogo. Estudos de Psicologia (Natal), 2(1), 7-27.

Martin-Baró, I. (1986/2011). Para uma Psicologia da Libertação. In: Guzzo, R. S. L., \& Lacerda Jr., F. (Orgs). Psicologia Social para a América Latina: o resgate da Psicologia da Libertação (pp. 101-120). Campinas: Editora Alínea.

Montero, M. (2004). Introducción a la Psicología Comunitaria: Desarrollo, conceptos y procesos. Buenos Aires: Paidós.

Moraes, M. (2008). Integral healthcare model for treating problems caused by alcohol and other drugs: perceptions of users, their companions and practitioners. Ciên. saúde colet., 13(1), 121-133.

Moretti-Pires, R. O., Lima, L. A. M., \& Katsurayama, M. (2010). A formação dos médicos de saúde da família no interior da Amazônia sobre a problemática do abuso de álcool. Rev. bras. prom. saúde, 23(1), 56-62. 
Rocha, M. L., \& Aguiar, K. F. (2003). Pesquisaintervenção e a produção de novas análises. Psicologia: Ciência e Profissão, 23(4), 64-73.

Ronzani, T. M. (2007). A Reforma Curricular nos Cursos de Saúde: Qual o Papel das Crenças? Revista Brasileira de Educação Médica, 31(1), 38-43.

Saforcada, E. T. (2008). El Concepto de Salud Comunitaria ¿Denomina solo un escenario de trabajo o también una nueva estrategia de acción en salud pública? Psicol. pesq., 2(2), 3-13.

Saforcada, E. T. (2012). Salud comunitaria, gestión de salud positiva y determinantes sociales de la salud y la enfermedad. Aletheia, 37(1), 7-22.

Saforcada, E. T., \& Alves, M. M. (2015). Saúde Comunitária: do novo paradigma às novas práticas em saúde. In: Sarriera, J. C., Saforcada, E. T., \& Alfaro, J. I. (Orgs.). Perspectiva Psicossocial na Saúde Comunitária. A comunidade como protagonista (pp. 19-48). Porto Alegre: Sulina.

Sarriera, J. C. (2010). A Investigação-Ação-Participante. In: Sarriera, J. C., \& Saforcada, E. T. (Orgs.). Introdução à Psicologia Comunitária (pp. 155-168). Porto Alegre: Editora Sulina.

Schneider, D. R. (2010). Horizonte de racionalidade acerca da dependência de drogas nos serviços de saúde: implicaçôes para o tratamento. Ciên. saúde colet., 15(3), 687-98.

Streck, D. R. (2016). Metodologias participativas de pesquisa e educação popular: reflexôes sobre critérios de qualidade. Interface (Botucatu), 20(58), 537-547.
Uzzell, D., \& Barnett, J. (2010). Pesquisa Etnográfica e Pesquisa-Ação. In: Breakwell, G. M. et al. (Orgs.) Métodos de Pesquisa em Psicologia (pp. 302-320). São Paulo: Artmed.

Valladares, L. (2007). Os dez mandamentos da observação participante. Revista Brasileira de Ciências Sociais, 22(63), 153-155.

Vargas, D., \& Duarte, F. A. B. (2011). Enfermeiros dos centros de atenção psicossocial em álcool e drogas (Caps ad): a formação e a busca pelo conhecimento específico da área. Texto contexto - enferm., 20(1), 119-26.

Yamamoto, O. H. (2009). Questão social e políticas públicas: Revendo o compromisso da psicologia. Em A. M. B. Bock (Org.), Psicologia e compromisso social (pp. 37-54). São Paulo: Cortez Editora.

Yamamoto, O. H., \& Oliveira, I. F. (2010). Política Social e Psicologia: uma trajetória de 25 anos. Psicologia: Teoria e Pesquisa, 26(spe), 9-24.

\section{Endereço para correspondência:}

Pedro Antunes Costa

Instituto de Ciências Humanas. Sala B-III-21

Rua José Lourenço Kelmer, s/n

CEP: 36036-900 - Juíz de Fora/MG

E-mail: phantunes.costa@gmail.com

Recebido em 06/05/2017

Aceito em 11/08/2017 